\title{
Phase II Trial of Metronomic Capecitabine and Cyclophosphamide with Lapatinib and Trastuzumab in Patients with HER2 Positive Metastatic Breast Cancer Who Have Progressed on a Previous Trastuzumab- Based Regimen
}

Irene Kang ( $\boldsymbol{Q}$ irene.kang@med.usc.edu )

University of Southern California

Peter D. Zang

LAC+USC Medical Center

\section{Darcy V. Spicer}

University of Southern California

Janice M. Lu

University of Southern California

\section{Susan Groshen}

University of Southern California

Denice Tsao-Wei

University of Southern California

Augustin A. Garcia

Louisiana State University System

\section{Research Article}

Keywords: Metronomic chemotherapy, HER2 positive breast cancer

Posted Date: March 8th, 2022

DOI: https://doi.org/10.21203/rs.3.rs-1349269/v2

License: (a) (i) This work is licensed under a Creative Commons Attribution 4.0 International License.

Read Full License 


\section{Abstract}

\section{Background:}

Breast cancer is the most common cancer and second most common cause of cancer mortality in women. Around $25 \%$ of all breast cancers have overexpression of Human Epidermal growth factor 2 (HER2), which is associated with earlier recurrence and shorter overall survival. 'Metronomic chemotherapy' is an emerging paradigm in cancer therapy, in which frequent low doses of chemotherapeutic agents are administered at frequent intervals. We proposed a regimen with metronomic chemotherapy with dual HER2 inhibition in HER2 positive patients with MBC. We hypothesize that this regimen will be highly active in $\mathrm{MBC}$ and have a favorable toxicity profile.

\section{Methods:}

This was a single-center, phase II, single arm, open-label study. Female patients 18 years of age and older who had histologically confirmed HER2-positive metastatic breast cancer with prior trastuzumab use in the adjuvant or metastatic setting were eligible. Patients were treated on a 21-day cycle with capecitabine $1500 \mathrm{mg}$ PO daily, cyclophosphamide 50mg PO daily, lapatinib 1000mg PO daily and trastuzumab $6 \mathrm{mg} / \mathrm{kg}$ IV once per 21-day cycle. The primary objective of this study was to estimate the progression free survival (PFS). Secondary objectives were to evaluate the overall response rate (ORR), to evaluate the clinical benefit rate (CBR; complete response, partial response, and stable disease for $\geq 24$ weeks), to estimate the overall survival (OS) and to assess the safety and tolerability of this regimen in the study population.

\section{Results:}

Ten patients were accrued for the study. PFS was 13.7 (95\% Cl: $2.6,16.6)$ months. ORR was $40 \%(95 \% \mathrm{Cl}$ : $15 \%, 70 \%)$, and CBR was $70 \%$. Median OS was 29.6 (95\% Cl: 11.8, 81.9+) months. Several grade 3 toxicities were identified in 5 patients (50\%): diarrhea, weight loss, fatigue, infusion related reaction, abdominal pain, oral mucositis, paronychia, AST and ALT increase, neutropenia, leukopenia and palmarplantar erythrodysesthesia.

\section{Conclusions:}

The proposed regimen of metronomic capecitabine and cyclophosphamide with lapatinib and trastuzumab appears to be active in patients with HER2 positive MBC but with toxicity in line with other standard therapies.

Trial Registration: ClinicalTrials.gov \# NCT01873833 Date: June 10, 2013

\section{Background}


Breast cancer is the most common cancer and second most common cause of cancer mortality in women (1). Approximately $20 \%$ of patients will be diagnosed with metastatic breast cancer (MBC) initially, while of the patients with initial localized disease, $30 \%$ will ultimately develop metastatic disease. Despite recent advances in therapy, metastatic breast cancer remains an incurable disease with a 5-year survival of $23 \%(2-4)$.

Around 25-30\% of all breast cancers have overexpression of Human Epidermal growth factor 2 (HER2), which is associated with earlier recurrence and shorter overall survival (5). Trastuzumab, a recombinant humanized monoclonal antibody against the extracellular domain of HER2, is an integral part of the treatment of HER2-positive breast cancer. Studies have shown that trastuzumab improves disease-free and overall survival in HER2 positive patients in both the adjuvant and metastatic disease settings (6-9). Trastuzumab monotherapy for HER2-positive MBC has a response rate of $13-26 \%$ and, in combination with chemotherapy such as taxanes and vinorelbine, response rates are $60-70 \%$ in the first line setting (10-13). However, patients invariably progress after initial response and the response rates often decrease in subsequent lines of therapy.

Lapatinib is an orally active small molecule that inhibits the tyrosine kinases of HER2 and epidermal growth factor receptor type 1 (EGFR). A phase III, randomized, open-label study showed that lapatinib in combination with capecitabine is also active in women with HER2-positive MBC who had previously received trastuzumab (14). The overall response rate for the combination therapy was $22 \%$, compared to $14 \%$ for patients receiving capecitabine monotherapy $(P=0.09)$. The median time to progression was 8.4 months with the combination therapy and 4.4 months with monotherapy $(P<0.001)$. The treatment was well tolerated, with the most common grade $\geq 3$ toxicities being diarrhea (13\%) and hand and foot syndrome (7\%). Therefore, the combination of lapatinib and capecitabine now represents a standard approach for patients with HER2-positive MBC after treatment with trastuzumab. Trastuzumab and lapatinib have non-overlapping mechanisms of action, and synergistic interaction between these two agents has been well characterized in in-vitro breast cancer models (15). In a randomized phase III study of patients with trastuzumab-refractory HER2 positive MBC, lapatinib 1000mg daily in combination with trastuzumab $2 \mathrm{mg} / \mathrm{kg}$ weekly (after initial $4 \mathrm{mg} / \mathrm{kg}$ loading dose) showed an improved median progression-free survival of 12 weeks compared to 8 weeks with lapatinib alone $(P=0.008)(16)$. Adverse events were similar in both groups, with a higher rate of grade 1-2 diarrhea with combination therapy. These studies suggest that dual HER2 inhibition is better than single agent anti-HER2 therapy in the treatment of HER2-positive breast cancer.

'Metronomic chemotherapy' is an emerging new paradigm in cancer therapy, in which frequent low doses of chemotherapeutic agents are administered at frequent intervals. Metronomic chemotherapy targets the endothelial cells that are dividing in the growing blood vessels of tumors, rather than the tumor cells themselves, resulting in an anti-angiogenic effect $(17,18)$. In preclinical models, virtually every class of chemotherapeutic agent has been shown to inhibit angiogenesis, which contributes to their antitumor efficacy (19). However, the anti-angiogenic effects of chemotherapy are masked by the long breaks between drug administrations, which enable the tumor vasculature to be repaired. Frequent low-dose 
therapy has been shown to have impressive anti-angiogenic and antitumor effects in mice along with reduced toxicity (20). This type of regimen has also been shown to have immunostimulatory effects particularly with low dose cyclophosphamide having a suppressive effect on $\mathrm{T}_{\text {reg }}$ cells thereby allowing CD4, CD8, and NK cells exert their antitumor activity uninhibited (21). Lastly, frequent low-dose therapy has also shown to induce senescence in cancer as compared to conventional dosing (22).

The major advantage of metronomic chemotherapy is the low toxicity, which significantly improves patients' quality of life, enables prolonged administration of chemotherapeutic agents without dose reductions or delays, and provides opportunities to combine different classes of agents that would otherwise be difficult with full dose regimens. Ideally metronomic chemotherapy would be administered daily. However, there are few chemotherapy agents that are available in an oral formulation. Nonetheless, the administration of a daily oral outpatient regimen has the additional practical benefit of decreasing clinic visits for patients. These benefits are most pronounced in the setting of metastatic cancer, where the goal is to prolong survival while maintaining quality of life for as long as possible. In addition, Bocci et al. did a pharmacoeconomic review of metronomic regimens in the setting of palliative treatment for metastatic cancer and found it could reduce costs relieving a financial burden to both patients and their caretakers providing another distinct advantage for these patients (23).

Metronomic chemotherapy has been found to have moderate activity with low toxicity in several phase II clinical trials in patients with MBC (24). In one of the largest series of patients with MBC with triple negative disease treated with metronomic chemotherapy, the VICTOR- 6 study showed an ORR of $17.5 \%$ with a median PFS of 6 months as well as a median OS of 12.1 months (25). Another phase II trial studying specifically HER2 positive MBC patients showed an ORR of $56.7 \%$. Median PFS was 11 months and median OS of 45.9 months (26). These trials show promising results and as such metronomic chemotherapy is becoming an increasingly recognized mode of therapy having been included in the ESMO 2020 guidelines on advanced breast cancer treatment including in the context of HER2 positivity (27).

We proposed a regimen with metronomic chemotherapy (capecitabine and cyclophosphamide) with dual HER2 inhibition (lapatinib and trastuzumab) in HER2 positive patients with MBC. We hypothesize that this regimen will be highly active in $\mathrm{MBC}$ and have a favorable toxicity profile.

\section{Methods}

We conducted this single-center, phase II, single arm, open-label study. Participants were recruited for Los Angeles County + University of Southern California (LAC + USC) Healthcare Network and the Keck Medical Center of USC, Norris Comprehensive Cancer Center in Los Angeles, California (ClinicalTrials.gov \# NCT01873833).

Female patients 18 years of age and older who had histologically confirmed HER2-positive metastatic breast cancer with prior trastuzumab use in the adjuvant or metastatic setting were eligible. No more than 
two prior cytotoxic chemotherapeutic regimens for metastatic breast cancer were allowed. Prior Trastuzumab emtansine (T-DM1, Kadcyla) was allowed. HER2 overexpression of tumor was determined by either immunohistochemistry $(\mathrm{IHC})$ or fluorescence in situ hybridization (FISH). Eligibility required tumors tested by $\mathrm{IHC}$ to be $3+$ positive or FISH to have a ratio of HER2:CEP17 > 2.0. When both tests were performed, the FISH result was required to be positive. Additional eligibility criteria were as follows: (1) measurable or unmeasurable disease by Response Evaluation Criteria In Solid Tumors (RECIST; version 1.1), with adequate organ and bone marrow function and an Eastern Cooperative Oncology Group performance status of $\leq 2$; (2) fully recovered from any toxicity due to prior therapy; (3)appropriate use of contraception during the course of the study and for 3 months following discontinuation of study treatments; (4) women of child-bearing potential must have negative pregnancy test at screening and enrollment.

Patients were ineligible if they had prior treatment with capecitabine or lapatinib, radiation or hormonal therapy within 2 weeks before study treatment, chemotherapy within 3 weeks before study treatment, biologic therapy (other than trastuzumab) or any other investigational agent within 4 weeks of study treatment, major surgery within 4 weeks before study treatment. Untreated, symptomatic, or progressive brain metastases were not allowed. Left ventricular ejection fraction $\leq 50 \%$ by MUGA or echocardiogram, warfarin use, human immunodeficiency virus (HIV) positivity, active hepatic or biliary disease were also exclusion criteria.

The primary objective of this study was to estimate the progression free survival (PFS) of metronomic chemotherapy with lapatinib and trastuzumab in patients with HER2 positive MBC who have progressed on prior trastuzumab-based therapy. Secondary objectives were to evaluate the overall response rate (ORR), to evaluate the clinical benefit rate (CBR; complete response, partial response, and stable disease for $\geq 24$ weeks), to estimate the overall survival (OS) and to assess the safety and tolerability of this regimen in the study population.

\section{Ethical Approval}

and Consent:

Written informed consent was obtained from all patients. The study protocol and any modifications were approved by a University of Southern California Institutional Review Board (IRB). The trial was conducted in accordance with the Good Clinical Practice guidelines and Declaration of Helsinki. An independent data monitoring committee assessed the safety data.

Treatment:

Patients were treated on a 21-day cycle with capecitabine $1500 \mathrm{mg}$ PO daily, cyclophosphamide 50mg daily, lapatinib $1000 \mathrm{mg}$ PO daily and trastuzumab $6 \mathrm{mg} / \mathrm{kg}$ IV once per 21-day cycle. This regimen was continued until disease progression or unacceptable toxicity. Other reasons to come off treatment 
included other intercurrent illness preventing further administration of treatment, patient decision to come off study, or changes in patient condition that render them unacceptable for further treatment.

Data collection:

Adverse events (AE) were graded according to the National Cancer Institute ( $\mathrm{NCl}$ ) Common Toxicity Criteria for Adverse Events (CTCAE) version 4.0 and were assessed at the start of each 21-day cycle. Participants experiencing one or more AEs due to the study treatment were were allowed dose interruption and/or dose reduction for capecitabine, cyclophosphamide, lapatinib and/or trastuzumab. Specific symptom management guidelines for cardiac and respiratory events, diarrhea, hepatotoxicity, skin disorders were outlined in the protocol and are available in the appendix. If the incidence of unacceptable toxicity was greater than $15 \%$ the study would be terminated. Unacceptable toxicity was defined as Grade 4 hematologic toxicity not resolving to Grade 1 at next lab check in 1 week, Grade 3 thrombocytopenia with bleeding, or any Grade 3 or 4 toxicity not resolving to Grade 1 or less within 96 hours despite supportive care. Response was assessed using RECIST v1.1 criteria, every 2 cycles.

The accrual goal was 40 patients over 24 months.

\section{Results}

Ten patients were accrued between January 2014 and October 2016. Median age was 52 (range 38-79) years. All patients had ECOG performance status $0-1$. At initial diagnosis, 2 patients presented with stage IV disease and 8 patients initially had stage II or III disease treated with chemotherapy and surgery with or without hormonal therapy for primary disease. Median number of chemotherapy regimens for metastatic disease was 0.5 (range $0-2$ ). (Table 1.) 
Table 1

Patients Demographics and Baseline Clinical Characteristics

\begin{tabular}{|c|c|c|}
\hline & Number Patients & Percent \\
\hline Total Eligible Patients & 10 & $100 \%$ \\
\hline Enrollment Time & $01 / 27 / 14-10 / 25 / 16$ & \\
\hline \multicolumn{3}{|l|}{ Age at Study Entry (yrs.) } \\
\hline Median (Range) & $52(38-79)$ & \\
\hline \multicolumn{3}{|l|}{ ECOG } \\
\hline 0 & 4 & $40 \%$ \\
\hline 1 & 6 & $60 \%$ \\
\hline \multicolumn{3}{|l|}{ Stage at Diagnosis } \\
\hline II & 5 & $50 \%$ \\
\hline III & 3 & $30 \%$ \\
\hline IV & 2 & $20 \%$ \\
\hline \multicolumn{3}{|l|}{ Histology } \\
\hline Ductal Infiltrating Carcinoma & 10 & $100 \%$ \\
\hline \multicolumn{3}{|l|}{ Histology Grade } \\
\hline 3 & 2 & $20 \%$ \\
\hline 4 & 8 & $80 \%$ \\
\hline \multicolumn{3}{|l|}{ Prior Surgery } \\
\hline No & 1 & $10 \%$ \\
\hline Resection of Primary & 9 & $90 \%$ \\
\hline \multicolumn{3}{|l|}{ Prior Chemotherapy } \\
\hline Yes & 10 & $100 \%$ \\
\hline Neoadjuvant Chemotherapy & 4 & $40 \%$ \\
\hline Adjuvant Chemotherapy & 8 & $80 \%$ \\
\hline Treated for Metastatic or Recurrent Disease & 7 & $70 \%$ \\
\hline \multicolumn{3}{|l|}{ Prior Chemotherapy Regimens } \\
\hline Median (Range) & $1(1-3)$ & \\
\hline
\end{tabular}




\begin{tabular}{|c|c|c|}
\hline & Number Patients & Percent \\
\hline \multicolumn{3}{|c|}{ Prior Chemotherapy Regimens for Metastatic Disease } \\
\hline Median (Range) & $0.5(0-2)$ & \\
\hline \multicolumn{3}{|c|}{ Prior Trastuzumab } \\
\hline Yes & 10 & $100 \%$ \\
\hline \multicolumn{3}{|l|}{ Prior T-DM1 } \\
\hline No & 6 & $60 \%$ \\
\hline Yes & 4 & $40 \%$ \\
\hline \multicolumn{3}{|l|}{ Prior Pertuzumab } \\
\hline No & 8 & $80 \%$ \\
\hline Yes & 2 & $20 \%$ \\
\hline \multicolumn{3}{|c|}{ Prior Hormone Therapy } \\
\hline No & 2 & $20 \%$ \\
\hline Yes & 8 & $80 \%$ \\
\hline \multicolumn{3}{|c|}{ Lymph Node Involvement at Baseline } \\
\hline No & 5 & $50 \%$ \\
\hline Yes & 5 & $50 \%$ \\
\hline \multicolumn{3}{|c|}{ Visceral Metastases at Baseline } \\
\hline No & 4 & $40 \%$ \\
\hline Yes & 6 & $60 \%$ \\
\hline
\end{tabular}

Study outcomes are summarized in Table 2. ORR was 40\% (95\% Cl: $15 \%, 70 \%)$, and CBR was $70 \%$. Median PFS was 13.7 (95\% Cl: 2.6, 16.6) months. Median OS was 29.6 (95\% Cl: 11.8, 81.9+) months (Fig. 1). Several grade 3 toxicities were identified in 5 patients (50\%): diarrhea, weight loss, fatigue, infusion related reaction, abdominal pain, oral mucositis, paronychia, AST and ALT increase, neutropenia, leukopenia and palmar-plantar erythrodysesthesia. The distribution of these toxicities is shown in Table 3. Early grade 3 toxicities (cycle 1 or 2) occurred in 3 of 5 patients (mucositis; infusion reaction and diarrhea; AST and ALT increase) and resolved to allow ongoing treatment in subsequent cycles. There were no grade 4 toxicities and a summary of all grade toxicities related to treatment are shown in Table 4. The most common toxicities of any grade were fatigue (100\%), diarrhea (80\%), anemia, neutropenia, ALT increase, nausea, rash and palmar-plantar erythrodysesthesia 50\% each. (Table 5). Two patients in our 
study achieved CR. One patient received 85 cycles of treatment prior to coming off protocol due to cumulative toxicity. This patient has continued on trastuzumab monotherapy with continued CR for 6.7 years as of last follow-up. During her treatment she underwent dose reductions of capecitabine for grade 2 neutropenia which was eventually discontinued at cycle 55. Lapatinib was dose reduced for paronychia four times and cyclophosphamide was dose reduced once for neutropenia. A second patient achieved CR after cycle 5 and maintained CR for 19 cycles then progressed (duration of response 54 weeks). One patient withdrew from study without response evaluation after receiving 2 cycles of treatment. A total of eight patients were taken off treatment due to disease progression. The trial was closed in 2020 due to lack of accrual. 
Table 2

Study Outcomes

\section{Number Patients}

Percent

Total Cycle of Treatment

$\leq 10$

4

$11-30$

5

1

$>30$

Median (Range)

$15.5(2-85)$

$40 \%$

$50 \%$

$10 \%$

1 st and 3rd quartile (4, 25)

Total Cycles Given 205

Grade 3 Or 4 Treatment Related Toxicity Observed

No

5

$50 \%$

Yes

5

$50 \%$

LVEF Decreased $20 \%$ or More Observed

No

10

$100 \%$

Complicated Diarrhea Observed

No

10

$100 \%$

Liver Event Observed

No

9

$90 \%$

Yes

1

$10 \%$

Treatment Held Due to Liver Function

Changed

No

9

$90 \%$

Treatment Stopped Due to Liver Function

Changed

No

10

$100 \%$

Severe Dermatologic Event

No

10 $100 \%$

*one patient received 2 cycles of treatment and withdrew study (treatment and follow-up) without disease evaluation

${ }^{\wedge}$ patient experienced grade 2 paronychia. 


\begin{tabular}{|c|c|c|}
\hline & Number Patients & Percent \\
\hline \multicolumn{3}{|l|}{ Best Response } \\
\hline CR & 2 & $20 \%$ \\
\hline PR & 2 & $20 \%$ \\
\hline SD & 5 & $50 \%$ \\
\hline Inevaluable & $1 *$ & $10 \%$ \\
\hline ORR (95\% Cl) & \multicolumn{2}{|l|}{$40 \%(15 \%, 70 \%)$} \\
\hline \multicolumn{3}{|c|}{ Clinical Benefit (CR/PR/SD > = 24 Weeks) } \\
\hline No & 2 & $20 \%$ \\
\hline Yes & 7 & $70 \%$ \\
\hline Inevaluable & $1 *$ & $10 \%$ \\
\hline \multicolumn{3}{|l|}{ Off Treatment } \\
\hline Yes & 10 & $100 \%$ \\
\hline \multicolumn{3}{|l|}{ Off Treatment Reason } \\
\hline Disease Progression & 8 & $89 \%$ \\
\hline Unacceptable $\mathrm{AE}^{\wedge}$ & 1 & $10 \%$ \\
\hline Refused Further Treatment & 1 & $10 \%$ \\
\hline \multicolumn{3}{|l|}{ Progression Free Survival } \\
\hline Median $(95 \% \mathrm{Cl})$ & \multicolumn{2}{|c|}{$13.7(2.6,16.6)$ Months } \\
\hline \multicolumn{3}{|l|}{ Overall Survival } \\
\hline Median $(95 \% \mathrm{Cl})$ & \multicolumn{2}{|l|}{$\begin{array}{l}29.6(11.8,81.9+) \\
\text { Months }\end{array}$} \\
\hline \multicolumn{3}{|l|}{ Duration of Follow-Up } \\
\hline Median (Range) & \multicolumn{2}{|l|}{$\begin{array}{l}50.1(1.3-81.9) \\
\text { Months }\end{array}$} \\
\hline \multicolumn{3}{|c|}{$\begin{array}{l}\text { *one patient received } 2 \text { cycles of treatment and withdrew study (treatment and follow-up) without } \\
\text { disease evaluation }\end{array}$} \\
\hline \multicolumn{3}{|c|}{ ^ patient experienced grade 2 paronychia. } \\
\hline
\end{tabular}


Table 3

Grade 3 Treatment Related Toxicities

\begin{tabular}{|c|c|c|c|}
\hline Patient & Toxicity & Grade & Cycle \\
\hline 1 & Weight loss & 3 & $6,7,10,12$ \\
\hline \multirow[t]{5}{*}{2} & Fatigue & 3 & 5,34 \\
\hline & Palmar-plantar erythrodysesthesia syndrome & 3 & $13,14,19,20,21,23,24$ \\
\hline & Paronychia & 3 & 34,35 \\
\hline & Neutrophil count decreased & 3 & 72 \\
\hline & White blood cell decreased & 3 & 54 \\
\hline \multirow[t]{2}{*}{3} & Diarrhea & 3 & 1,4 \\
\hline & Infusion related reaction & 3 & 1 \\
\hline 4 & Mucositis oral & 3 & $1,2,3$ \\
\hline \multirow[t]{2}{*}{5} & ALT (SGPT) & 3 & 2,3 \\
\hline & AST (SGOT) & 3 & 2,3 \\
\hline
\end{tabular}


Table 4

Toxicities Related to Study Treatment

\begin{tabular}{|c|c|c|c|c|c|}
\hline \multirow[t]{2}{*}{ Category } & \multirow[t]{2}{*}{ Toxicity } & \multicolumn{4}{|c|}{$\begin{array}{l}\text { Number Patients with Maximum } \\
\text { Grade Toxicity Experienced }\end{array}$} \\
\hline & & $\begin{array}{l}\text { Grade } \\
1\end{array}$ & $\begin{array}{l}\text { Grade } \\
2\end{array}$ & $\begin{array}{l}\text { Grade } \\
3\end{array}$ & $\begin{array}{l}\text { Grade } \\
\mathbf{4}\end{array}$ \\
\hline $\begin{array}{l}\text { Blood and Lymphatic System } \\
\text { Disorders }\end{array}$ & Anemia & 3 & 2 & 0 & 0 \\
\hline \multirow[t]{5}{*}{ Eye Disorders } & Blurred vision & 1 & 0 & 0 & 0 \\
\hline & Conjunctivitis & 0 & 2 & 0 & 0 \\
\hline & Dry eye & 2 & 0 & 0 & 0 \\
\hline & Eye disorders - Other & 0 & 1 & 0 & 0 \\
\hline & Watering eyes & 2 & 1 & 0 & 0 \\
\hline \multirow[t]{8}{*}{ Gastrointestinal Disorders } & Abdominal pain & 3 & 1 & 0 & 0 \\
\hline & Constipation & 1 & 1 & 0 & 0 \\
\hline & Diarrhea & 5 & 2 & 1 & 0 \\
\hline & Dry mouth & 2 & 0 & 0 & 0 \\
\hline & Dyspepsia & 2 & 0 & 0 & 0 \\
\hline & Mucositis oral & 2 & 1 & 1 & 0 \\
\hline & Nausea & 5 & 0 & 0 & 0 \\
\hline & Vomiting & 0 & 1 & 0 & 0 \\
\hline \multirow{3}{*}{$\begin{array}{l}\text { General Disorders and } \\
\text { Administration Site Conditions }\end{array}$} & Fatigue & 7 & 2 & 1 & 0 \\
\hline & Infusion related reaction & 0 & 0 & 1 & 0 \\
\hline & Pain & 0 & 1 & 0 & 0 \\
\hline Hepatobiliary Disorders & $\begin{array}{l}\text { Hepatobiliary disorders - } \\
\text { Other }\end{array}$ & 1 & 0 & 0 & 0 \\
\hline Infections and Infestations & Paronychia & 0 & 2 & 1 & 0 \\
\hline $\begin{array}{l}\text { Injury, Poisoning and } \\
\text { Procedural Complications }\end{array}$ & Bruising & 1 & 0 & 0 & 0 \\
\hline \multirow[t]{3}{*}{ Investigations-Hematologic } & $\begin{array}{l}\text { Neutrophil count } \\
\text { decreased }\end{array}$ & 2 & 2 & 1 & 0 \\
\hline & Platelet count decreased & 2 & 0 & 0 & 0 \\
\hline & White blood cell decreased & 1 & 2 & 1 & 0 \\
\hline
\end{tabular}




\begin{tabular}{|c|c|c|c|c|c|}
\hline \multirow[t]{2}{*}{ Category } & \multirow[t]{2}{*}{ Toxicity } & \multicolumn{4}{|c|}{$\begin{array}{l}\text { Number Patients with Maximum } \\
\text { Grade Toxicity Experienced }\end{array}$} \\
\hline & & $\begin{array}{l}\text { Grade } \\
1\end{array}$ & $\begin{array}{l}\text { Grade } \\
2\end{array}$ & $\begin{array}{l}\text { Grade } \\
3\end{array}$ & $\begin{array}{l}\text { Grade } \\
4\end{array}$ \\
\hline \multirow[t]{4}{*}{ Investigations-Hepatic } & ALT (SGPT) & 4 & 0 & 1 & 0 \\
\hline & AST (SGOT) & 3 & 0 & 1 & 0 \\
\hline & $\begin{array}{l}\text { Alkaline phosphatase } \\
\text { increased }\end{array}$ & 2 & 0 & 0 & 0 \\
\hline & Blood bilirubin increased & 0 & 2 & 0 & 0 \\
\hline $\begin{array}{l}\text { Investigations- } \\
\text { Renal/Genitourinary }\end{array}$ & Creatinine increased & 0 & 1 & 0 & 0 \\
\hline Investigations-Weight Loss & Weight loss & 0 & 0 & 1 & 0 \\
\hline \multirow{3}{*}{$\begin{array}{l}\text { Metabolism and Nutrition } \\
\text { Disorders }\end{array}$} & Anorexia & 3 & 1 & 0 & 0 \\
\hline & Hypokalemia & 1 & 1 & 0 & 0 \\
\hline & Hypomagnesemia & 2 & 0 & 0 & 0 \\
\hline \multirow{3}{*}{$\begin{array}{l}\text { Musculoskeletal and } \\
\text { Connective Tissue Disorders }\end{array}$} & Arthralgia & 3 & 0 & 0 & 0 \\
\hline & Back pain & 0 & 1 & 0 & 0 \\
\hline & Pain in extremity & 1 & 0 & 0 & 0 \\
\hline \multirow[t]{3}{*}{ Nervous System Disorders } & Dizziness & 1 & 0 & 0 & 0 \\
\hline & Dysgeusia & 3 & 0 & 0 & 0 \\
\hline & Paresthesia & 2 & 0 & 0 & 0 \\
\hline Psychiatric Disorders & Insomnia & 2 & 0 & 0 & 0 \\
\hline \multirow{4}{*}{$\begin{array}{l}\text { Respiratory, Thoracic and } \\
\text { Mediastinal Disorders }\end{array}$} & Dyspnea & 2 & 0 & 0 & 0 \\
\hline & Epistaxis & 1 & 0 & 0 & 0 \\
\hline & Pharyngeal mucositis & 0 & 1 & 0 & 0 \\
\hline & Sore throat & 1 & 0 & 0 & 0 \\
\hline \multirow{4}{*}{$\begin{array}{l}\text { Skin and subcutaneous tissue } \\
\text { disorders }\end{array}$} & Alopecia & 2 & 0 & 0 & 0 \\
\hline & Dry skin & 3 & 0 & 0 & 0 \\
\hline & Nail discoloration & 2 & 1 & 0 & 0 \\
\hline & Nail loss & 1 & 1 & 0 & 0 \\
\hline
\end{tabular}




\begin{tabular}{|c|c|c|c|c|c|}
\hline \multirow[t]{2}{*}{ Category } & \multirow[t]{2}{*}{ Toxicity } & \multicolumn{4}{|c|}{$\begin{array}{l}\text { Number Patients with Maximum } \\
\text { Grade Toxicity Experienced }\end{array}$} \\
\hline & & $\begin{array}{l}\text { Grade } \\
1\end{array}$ & $\begin{array}{l}\text { Grade } \\
2\end{array}$ & $\begin{array}{l}\text { Grade } \\
3\end{array}$ & $\begin{array}{l}\text { Grade } \\
\mathbf{4}\end{array}$ \\
\hline & $\begin{array}{l}\text { Palmar-plantar } \\
\text { erythrodysesthesia } \\
\text { syndrome }\end{array}$ & 2 & 2 & 1 & 0 \\
\hline & Pruritus & 2 & 1 & 0 & 0 \\
\hline & Rash acneiform & 1 & 0 & 0 & 0 \\
\hline & Rash maculo-papular & 4 & 0 & 0 & 0 \\
\hline & Skin hyperpigmentation & 2 & 0 & 0 & 0 \\
\hline
\end{tabular}


Table 5

Most Common Treatment Related Toxicities

\begin{tabular}{|c|c|c|c|c|}
\hline \multirow[t]{2}{*}{ Toxicity } & \multicolumn{2}{|c|}{ Any Grade Toxicity } & \multicolumn{2}{|c|}{ Grade 3 or 4 Toxicity } \\
\hline & $\begin{array}{l}\text { Number } \\
\text { Patients }\end{array}$ & Percent & $\begin{array}{l}\text { Number } \\
\text { Patients }\end{array}$ & Percent \\
\hline Fatigue & 10 & $100 \%$ & 1 & $10 \%$ \\
\hline Diarrhea & 8 & $80 \%$ & 1 & $10 \%$ \\
\hline ALT (SGPT) & 5 & $50 \%$ & 1 & $10 \%$ \\
\hline Anemia & 5 & $50 \%$ & & \\
\hline Nausea & 5 & $50 \%$ & & \\
\hline Neutrophil count decreased & 5 & $50 \%$ & 1 & $10 \%$ \\
\hline $\begin{array}{l}\text { Palmar-plantar erythrodysesthesia } \\
\text { syndrome }\end{array}$ & 5 & $50 \%$ & 1 & $10 \%$ \\
\hline Rash & 5 & $50 \%$ & & \\
\hline AST (SGOT) & 4 & $40 \%$ & 1 & $10 \%$ \\
\hline Abdominal pain & 4 & $40 \%$ & & \\
\hline Anorexia & 4 & $40 \%$ & & \\
\hline Mucositis oral & 4 & $40 \%$ & 1 & $10 \%$ \\
\hline White blood cell decreased & 4 & $40 \%$ & 1 & $10 \%$ \\
\hline Arthralgia & 3 & $30 \%$ & & \\
\hline Dry skin & 3 & $30 \%$ & & \\
\hline Dysgeusia & 3 & $30 \%$ & & \\
\hline Nail discoloration & 3 & $30 \%$ & & \\
\hline Paronychia & 3 & $30 \%$ & 1 & $10 \%$ \\
\hline Pruritus & 3 & $30 \%$ & & \\
\hline Watering eyes & 3 & $30 \%$ & & \\
\hline Infusion related reaction & 1 & $10 \%$ & 1 & $10 \%$ \\
\hline Weight loss & 1 & $10 \%$ & 1 & $10 \%$ \\
\hline
\end{tabular}

Discussion 
In this study we have shown efficacy of a metronomic chemotherapy regimen in the treatment of HER2 positive MBC that has progressed after prior trastuzumab-based therapy. Other regimens for HER2 positive MBC after trastuzumab include capecitabine and lapatinib with a reported PFS of 6-8 months and T-DM1 with reported PFS of 9.6 months $(28,29)$. Our regimen suggests a comparable PFS of 13.7 months, ORR, CBR and OS however with a numerically high incidence of toxicity requiring dose modification and/or delay (grade 3 adverse event rate 50\%). Other capecitabine based regimens, such as combinations with lapatinib or tucatinib, report similar rates of grade 3 or 4 adverse events. Presumably, these events are mostly related to capecitabine. Our study used a lower dose of capecitabine but this did not translate into significant lower toxicity. Due to the lack of accrual, this study was closed with only ten patients accrued and only nine patients evaluable. This severely limits the conclusions for the primary and secondary endpoints mentioned above. Although the rate of toxicity reported with this regimen of metronomic chemotherapy was not numerically less than other standard regimens, its efficacy assessed by PFS was numerically superior to other regimens and may be at least comparable. It is conceivable that metronomic chemotherapy may still prove beneficial to patients if delivered in a different method.

The landscape of treatment for HER2 positive MBC has changed considerably since the execution of this study. Most notably with the introduction of pertuzumab in first line therapy and T-DM1 in the second line $(28,30)$. While T-DM1 was allowed for this study population, very few patients were treated prior to enrollment. The study was closed prior to widespread availability of subsequently FDA approved HER2 therapeutics such as tucatinib, trastuzumab-deruxtecan, and neratinib. These new therapies have shown impressive responses though with some noted toxicity. The NALA trial evaluating neratinib in combination with capecitabine showed a median PFS of 8.8 months but with $60.7 \%$ of patients experiencing a grade 3 or higher adverse event (31). The HER2CLIMB study regimen of tucatinib, capecitabine, herceptin reported a median PFS of 7.8 months with $55.2 \%$ patients experiencing a grade 3 or higher adverse event (32). In a phase II trial of trastuzumab-deruxtecan in heavily pre-treated patients, there was a median PFS of 16.4 months but with $52.2 \%$ of patients experiencing a grade 3 or higher adverse event (33). More recently, the results of the DESTINY Breast03 trial showed a notable $72 \%$ reduction in risk of disease progression for trastuzumab-deruxtecan when compared to T-DM1 in patients previously treated with taxane and trastuzumab and may soon become the preferred second-line agent (34). These newly approved HER2 therapeutics show a toxicity profile not too different from our study regimen. This could suggest that combinations with these new HER2 therapeutics in a metronomic based regimen may improve tolerability given a likely significant contributor in toxicity in our study's regimen was lapatinib, which has shown to have notable toxicity when given as a monotherapy (16). In addition, there have been new promising advancements in immunotherapy particularly immune checkpoint inhibitors and their utility in HER2 positive MBC. Both the PANACEA and KATE2 trial utilized immune checkpoint inhibitors in combination with HER2 targeted therapy in patients with HER2 positive MBC who progressed on trastuzumab therapy; the results showed durable responses though these results were only seen in patients who had tumors with high PDL-1 expression $(35,36)$. While this changing landscape makes it more difficult to put this study into present day context, the findings suggest that a metronomic chemotherapy regimen could prove useful with further study. For example, combinations with other 
targeted agents such as tyrosine kinase inhibitors (tucatinib, neratinib) or checkpoint inhibitors might yield more favorable efficacy and toxicity profiles (32). Managing toxicity is important in all disease settings and in early stage HER2 + disease, a de-escalated targeted regimen has demonstrated excellent response rates and overall survival with similar studies ongoing $(37,38)$. For advanced stage disease, managing toxicity should be prioritized in the treatment paradigm given the palliative nature of therapy.

Despite the evolving landscape in HER2 positive MBC, metronomic chemotherapy may still be a viable and preferable option for certain patients. Although our study in HER2 positive MBC patients was limited by both patient accrual and toxicity, the efficacy of the regimen proved to be either numerically superior or at least comparable to standard regimens. It is possible that with further investigation of different methods of delivery that metronomic chemotherapy may still be beneficial for advanced stage patients where it could minimize symptom burden and improve quality of life for patients. Exploring the combination of metronomic capecitabine, using a lower dose than used in our trial, with trastuzumab and tucatinib may be worth exploring with goal of minimizing toxicity while maintain efficacy

\section{Conclusion}

The proposed regimen of metronomic capecitabine and cyclophosphamide with lapatinib and trastuzumab appears to be active in patients with HER2 positive MBC but with toxicity in line with other standard therapies.

\section{Abbreviations}

AE Adverse Event

CBR Clinical Benefit Rate

CR Complete Response

CTCAE Common Terminology Criteria for Adverse Events

ECOG Eastern Cooperative Oncology Group

EGFR Epidermal Growth Factor Receptor

ESMO European Society of Medical Oncology

FISH Fluorescence In Situ Hybridization

HER2 Human Epidermal Growth Factor 2

IHC Immunohistochemistry

MBC Metastatic Breast Cancer 
MUGA Multi-gated Acquisition

ORR Overall Response Rate

OS Overall Survival

PFS Progression-Free Survival

RECIST Response Evaluation Criteria In Solid Tumors

T-DM1 Trastuzumab Emtansine

\section{Declarations}

Ethics approval and consent to participate:

The study protocol was approved by the Institutional Review Board University of Southern California and was conducted in accordance with the Declaration of Helsinki, Good Clinical Practice, and all local and federal regulatory guidelines. Informed consent was obtained from all individual participants included in the study

Consent for publication: Not applicable

Availability of data and materials:

All data generated or analyzed during this study are included in this published article and its supplementary information files.

Competing interests: Janice M Lu reports the following competing interests to disclose: Honoraria: Daiichi Sankyo; Novartis; Pfizer; Puma Biotechnology. Consulting or Advisory Role - Daiichi Sankyo/Lilly; Novartis; Pfizer; Puma Biotechnology. Travel, Accommodations, Expenses - Daiichi Sankyo; Novartis; Pfizer. Agustin A Garcia has the following competing interests to disclose: Honoraria: Pfizer. Consulting or Advisory Role - Amgen; Novartis. Research Funding - Advenchen Laboratories (Inst); Boston Biomedical (Inst); Celldex (Inst). Irene M Kang has the following competing interests to disclose: Honoraria- Bristol Myer Squibb; Puma Biotechnology. Speaker's Bureau: Puma Biotechnology.

All other authors declare that they have no competing interests.

Funding:

Top of Form

The project described was supported by award number P30CA014089 from the National Cancer Institute. The content is solely the responsibility of the authors and does not necessarily represent the official views of the National Cancer Institute or the National Institutes of Health. 
Authors' contributions:

AAG conceptualized and designed the study with statistical design input from SG. Results were analyzed by IK and AAG. IK and PDZ wrote the manuscript. DT and SG performed statistical analysis. All authors, including JML, DVS read and approved the final manuscript.

Acknowledgements: We thank the patients who participated in this study and the study coordinator staff who supported these research efforts.

Authors' information (optional)

Affiliations

University of Southern California, Norris Comprehensive Cancer Center - Division of Oncology, Los Angeles, CA

Irene M Kang, Janice M Lu, Darcy V Spicer

Univeristy of Southern Cailfornia, Norris Comprehensive Cancer Center - Biostatistics Core, Los Angeles, CA

Susan Groshen, Denise Tsao-Wei

LAC+USC Medical Center, Los Angeles, CA

Peter Zang

Louisiana State University School of Medicine - Section of Hematology/Oncology, New Orleans, LA Agustin A Garcia

\section{References}

1. Sancho-Garnier H, Colonna M. [Breast cancer epidemiology]. Presse Med. 2019;48(10):1076-84. doi 10.1016/j.lpm.2019.09.022.

2. Klar N, Rosenzweig M, Diergaarde B, Brufsky A. Features Associated With Long-Term Survival in Patients With Metastatic Breast Cancer. Clin Breast Cancer. 2019;19(4):304-10. doi 10.1016/j.clbc.2019.01.014.

3. Malmgren JA, Calip GS, Atwood MK, Mayer M, Kaplan HG. Metastatic breast cancer survival improvement restricted by regional disparity: Surveillance, Epidemiology, and End Results and institutional analysis: 1990 to 2011. Cancer. 2020;126(2):390-9. doi 10.1002/cncr.32531.

4. Redig AJ, McAllister SS. Breast cancer as a systemic disease: a view of metastasis. J Intern Med. 2013;274(2):113-26. doi 10.1111/joim.12084. 
5. Cobleigh MA, Vogel CL, Tripathy D, Robert NJ, Scholl S, Fehrenbacher L, et al. Multinational study of the efficacy and safety of humanized anti-HER2 monoclonal antibody in women who have HER2overexpressing metastatic breast cancer that has progressed after chemotherapy for metastatic disease. J Clin Oncol. 1999;17(9):2639-48. doi 10.1200/JC0.1999.17.9.2639.

6. Lv S, Wang Y, Sun T, Wan D, Sheng L, Li W, et al. Overall Survival Benefit from Trastuzumab-Based Treatment in HER2-Positive Metastatic Breast Cancer: A Retrospective Analysis. Oncol Res Treat. 2018;41(7-8):450-5. doi 10.1159/000488202.

7. Baselga J, Perez EA, Pienkowski T, Bell R. Adjuvant trastuzumab: a milestone in the treatment of HER-2-positive early breast cancer. Oncologist. 2006;11(Suppl 1):4-12. doi 10.1634/theoncologist.11-90001-4.

8. Slamon DJ, Leyland-Jones B, Shak S, Fuchs H, Paton V, Bajamonde A, et al. Use of Chemotherapy plus a Monoclonal Antibody against HER2 for Metastatic Breast Cancer That Overexpresses HER2. N Engl J Med. 2001;344(11):783-92. doi 10.1056/NEJM200103153441101.

9. Piccart-Gebhart MJ, Procter M, Leyland-Jones B, Goldhirsch A, Untch M, Smith I, et al. Trastuzumab after Adjuvant Chemotherapy in HER2-Positive Breast Cancer. N Engl J Med. 2005;353(16):1659-72. doi 10.1056/NEJMoa052306.

10. Papaldo P, Fabi A, Ferretti G, Mottolese M, Cianciulli AM, Di Cocco B, et al. A phase II study on metastatic breast cancer patients treated with weekly vinorelbine with or without trastuzumab according to HER2 expression: changing the natural history of HER2-positive disease. Ann Oncol. 2006;17(4):630-6. doi 10.1093/annonc/mdj110.

11. Burstein HJ, Harris LN, Marcom PK, Lambert-Falls R, Havlin K, Overmoyer B, et al. Trastuzumab and vinorelbine as first-line therapy for HER2-overexpressing metastatic breast cancer: multicenter phase II trial with clinical outcomes, analysis of serum tumor markers as predictive factors, and cardiac surveillance algorithm. J Clin Oncol. 2003;21(15):2889-95. doi 10.1200/JC0.2003.02.018.

12. Romond EH, Perez EA, Bryant J, Suman VJ, Geyer CE, Davidson NE, et al. Trastuzumab plus Adjuvant Chemotherapy for Operable HER2-Positive Breast Cancer. N Engl J Med. 2005;353(16):1673-84. doi 10.1056/NEJMoa052122.

13. Vogel CL, Cobleigh MA, Tripathy D, Gutheil JC, Harris LN, Fehrenbacher L, et al. Efficacy and safety of trastuzumab as a single agent in first-line treatment of HER2-overexpressing metastatic breast cancer. J Clin Oncol. 2002;20(3):719-26. doi 10.1200/JC0.2002.20.3.719.

14. Cameron D, Casey M, Press M, Lindquist D, Pienkowski T, Romieu CG, et al. A phase III randomized comparison of lapatinib plus capecitabine versus capecitabine alone in women with advanced breast cancer that has progressed on trastuzumab: updated efficacy and biomarker analyses. Breast Cancer Res Treat. 2008;112(3):533-43. doi 10.1007/s10549-007-9885-0.

15. Scaltriti M, Verma C, Guzman M, Jimenez J, Parra JL, Pedersen K, et al. Lapatinib, a HER2 tyrosine kinase inhibitor, induces stabilization and accumulation of HER2 and potentiates trastuzumabdependent cell cytotoxicity. Oncogene. 2009;28(6):803-14. doi 10.1038/onc.2008.432. 
16. Blackwell KL, Burstein HJ, Storniolo AM, Rugo H, Sledge G, Koehler M, et al. Randomized Study of Lapatinib Alone or in Combination With Trastuzumab in Women With ErbB2-Positive, TrastuzumabRefractory Metastatic Breast Cancer. J Clin Oncol. 2010;28(7):1124-30. doi 10.1200/JCO.2008.21.4437.

17. Kim JY, Kim Y-M. Tumor endothelial cells as a potential target of metronomic chemotherapy. Arch Pharm Res. 2019;42(1):1-13. doi 10.1007/s12272-018-01102-z.

18. Browder T, Butterfield CE, Kraling BM, Shi B, Marshall B, O'Reilly MS, et al. Antiangiogenic scheduling of chemotherapy improves efficacy against experimental drug-resistant cancer. Cancer Res. 2000;60(7):1878-86.

19. Kerbel RS, Klement G, Pritchard KI, Kamen B. Continuous low-dose anti-angiogenic/ metronomic chemotherapy: from the research laboratory into the oncology clinic. Ann Oncol. 2002;13(1):12-5. doi 10.1093/annonc/mdf093.

20. Man S, Bocci G, Francia G, Green SK, Jothy S, Hanahan D, et al. Antitumor effects in mice of low-dose (metronomic) cyclophosphamide administered continuously through the drinking water. Cancer Res. 2002;62(10):2731-5.

21. Lutsiak ME, Semnani RT, De Pascalis R, Kashmiri SV, Schlom J, Sabzevari H. Inhibition of CD4(+) $25+$ $T$ regulatory cell function implicated in enhanced immune response by low-dose cyclophosphamide. Blood. 2005;105(7):2862-8. doi 10.1182/blood-2004-06-2410.

22. Ewald JA, Desotelle JA, Wilding G, Jarrard DF. Therapy-induced senescence in cancer. J Natl Cancer Inst. 2010;102(20):1536-46. doi 10.1093/jnci/djq364.

23. Bocci G, Tuccori M, Emmenegger U, Liguori V, Falcone A, Kerbel RS, et al. Cyclophosphamidemethotrexate 'metronomic' chemotherapy for the palliative treatment of metastatic breast cancer. $A$ comparative pharmacoeconomic evaluation. Ann Oncol. 2005;16(8):1243-52. doi 10.1093/annonc/mdi240.

24. Colleoni M, Orlando L, Sanna G, Rocca A, Maisonneuve P, Peruzzotti G, et al. Metronomic low-dose oral cyclophosphamide and methotrexate plus or minus thalidomide in metastatic breast cancer: antitumor activity and biological effects. Ann Oncol. 2006;17(2):232-8. doi 10.1093/annonc/mdj066.

25. Cazzaniga ME, Pinotti G, Montagna E, Amoroso D, Berardi R, Butera A, et al. Metronomic chemotherapy for advanced breast cancer patients in the real world practice: Final results of the VICTOR-6 study. Breast. 2019;48:7-16. doi 10.1016/j.breast.2019.07.006.

26. Orlando L, Lorusso V, Giotta F, Di Maio M, Schiavone P, Fedele P, et al. Metronomic oral chemotherapy with cyclophosphamide plus capecitabine combined with trastuzumab (HEX) as first line therapy of HER-2 positive advanced breast cancer: A phase II trial of the Gruppo Oncologico Italia Meridionale (GOIM). Breast. 2020;53:18-22. doi 10.1016/j.breast.2020.06.002.

27. Cardoso F, Paluch-Shimon S, Senkus E, Curigliano G, Aapro MS, Andre F, et al. 5th ESO-ESMO international consensus guidelines for advanced breast cancer (ABC 5). Ann Oncol. 2020;31(12):1623-49. doi 10.1016/j.annonc.2020.09.010. 
28. Verma S, Miles D, Gianni L, Krop IE, Welslau M, Baselga J, et al. Trastuzumab emtansine for HER2positive advanced breast cancer. N Engl J Med. 2012;367(19):1783-91. doi

10.1056/NEJMoa1209124.

29. Geyer CE, Forster J, Lindquist D, Chan S, Romieu CG, Pienkowski T, et al. Lapatinib plus capecitabine for HER2-positive advanced breast cancer. N Engl J Med. 2006;355(26):2733-43. doi 10.1056/NEJMoa064320.

30. Swain SM, Baselga J, Kim SB, Ro J, Semiglazov V, Campone M, et al. Pertuzumab, trastuzumab, and docetaxel in HER2-positive metastatic breast cancer. N Engl J Med. 2015;372(8):724-34. doi 10.1056/NEJMoa1413513.

31. Saura C, Oliveira M, Feng Y-H, Dai M-S, Chen S-W, Hurvitz SA, et al. Neratinib Plus Capecitabine Versus Lapatinib Plus Capecitabine in HER2-Positive Metastatic Breast Cancer Previously Treated With $\geq 2$ HER2-Directed Regimens: Phase III NALA Trial. J Clin Oncol. 2020;38(27):3138-49. doi 10.1200/jco.20.00147.

32. Curigliano G, Mueller V, Borges VF, Hamilton EP, Hurvitz SA, Loi S, et al. Updated results of tucatinib versus placebo added to trastuzumab and capecitabine for patients with pretreated HER2 + metastatic breast cancer with and without brain metastases (HER2CLIMB). J Clin Oncol. 2021;39(15_suppl):1043- doi. 10.1200/JC0.2021.39.15_suppl.1043.

33. Modi S, Saura C, Yamashita T, Park YH, Kim S-B, Tamura K, et al. Trastuzumab Deruxtecan in Previously Treated HER2-Positive Breast Cancer. N Engl J Med. 2019;382(7):610-21. doi 10.1056/NEJMoa1914510.

34. Cortés J, Kim S, Chung W, et al: Trastuzumab deruxtecan (T-DXd) vs trastuzumab emtansine (T-DM1) in patients with HER2 + metastatic breast cancer: Results of the randomized phase III DESTINYBreast03 study. ESMO Congress 2021. Abstract LBA1. Presented September 18, 2021.

35. Loi S, Giobbie-Hurder A, Gombos A, Bachelot T, Hui R, Curigliano G, et al. Pembrolizumab plus trastuzumab in trastuzumab-resistant, advanced, HER2-positive breast cancer (PANACEA): a singlearm, multicentre, phase 1b-2 trial. Lancet Oncol. 2019;20(3):371-82. doi 10.1016/S14702045(18)30812-X.

36. Emens LA, Esteva FJ, Beresford M, Saura C, De Laurentiis M, Kim SB, et al. Trastuzumab emtansine plus atezolizumab versus trastuzumab emtansine plus placebo in previously treated, HER2-positive advanced breast cancer (KATE2): a phase 2, multicentre, randomised, double-blind trial. Lancet Oncol. 2020;21(10):1283-95. doi 10.1016/S1470-2045(20)30465-4.

37. Nitz UA, Gluz O, Christgen M, Grischke EM, Augustin D, Kuemmel S, et al. De-escalation strategies in HER2-positive early breast cancer (EBC): final analysis of the WSG-ADAPT HER2+/HR- phase II trial: efficacy, safety, and predictive markers for 12 weeks of neoadjuvant dual blockade with trastuzumab and pertuzumab +/- weekly paclitaxel. Ann Oncol. 2017;28(11):2768-72. doi 10.1093/annonc/mdx494.

38. Harbeck N, Gluz O, Christgen M, Kuemmel S, Grischke E-M, Braun M, et al. De-escalated neoadjuvant pertuzumab + trastuzumab with or without paclitaxel weekly in HR-/HER2 + early breast cancer: 
ADAPT-HR-/HER2 + biomarker and survival results. J Clin Oncol. 2021;39(15_suppl):503- doi. 10.1200/JCO.2021.39.15_suppl.503.

Figures

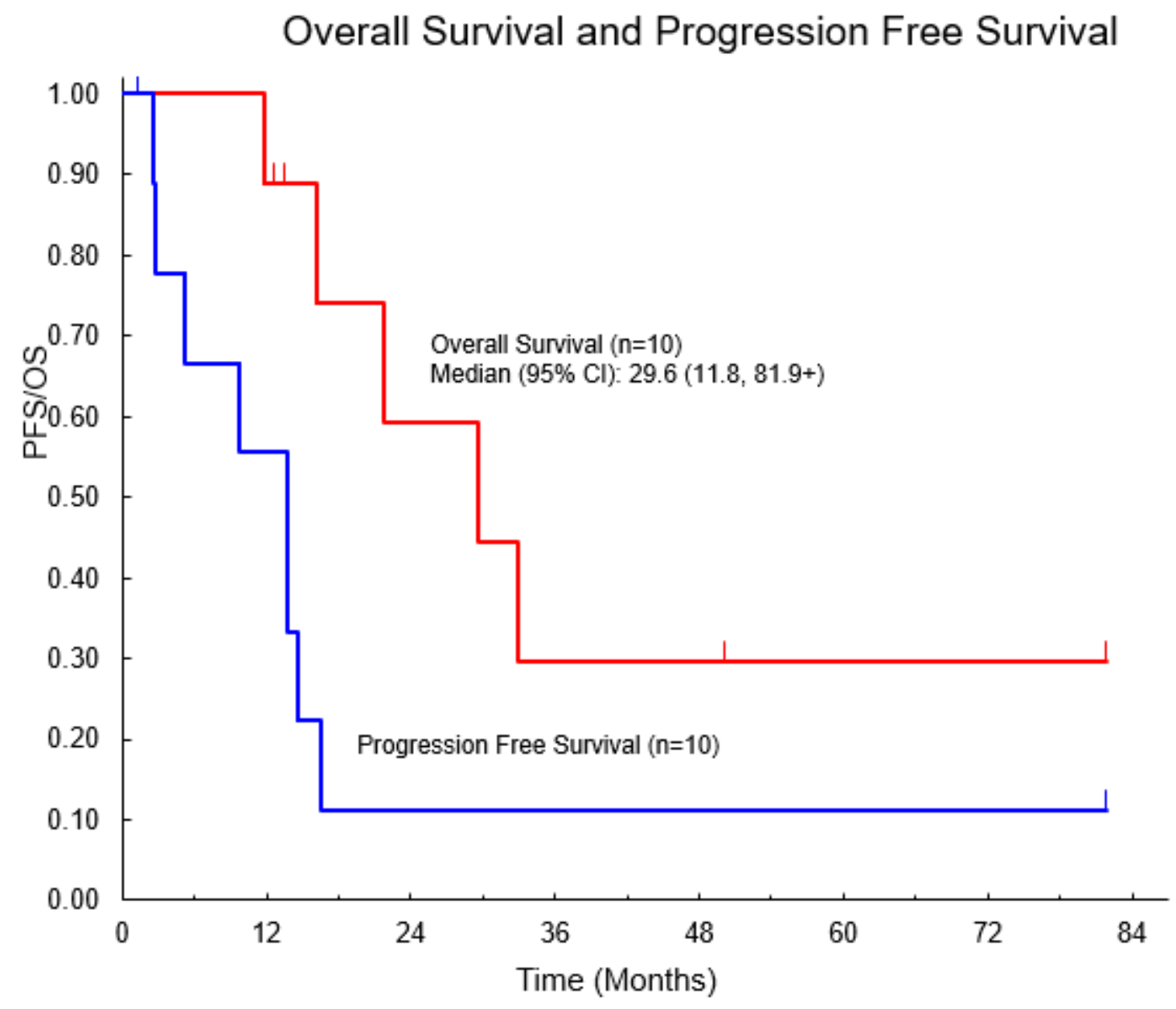

Figure 1

OS and PFS of Patients on Study

\section{Supplementary Files}

This is a list of supplementary files associated with this preprint. Click to download.

- MetronomicChemoTrialProtocol.pdf 